\title{
Identidad, transformación y retórica patrimonial en una ciudad minera del desierto de Atacama, Chile*
}

\author{
Juan Carlos Rodríguez Torrent y Pablo Miranda Bown
}

\begin{abstract}
El presente trabajo corresponde a un esfuerzo de síntesis y sistematización en términos teóricos y analíticos de materiales etnográficos recogidos durante la última década en la ciudad salitrera de María Elena, en el desierto de Atacama, Chile. Se discute sobre la formación de la identidad, la trayectoria y experiencia de sus habitantes; sobre la ciudad, que fue concebida bajo principios de la tradición utópica, y sus cambios en el emplazamiento. Se pone énfasis en el proceso de transformación a campamento y luego a un interés de patrimonialización del complejo urbano. Esta última forma, observada como manifestación de los cambios sufridos a partir del predominio de un nuevo modelo de acumulación, cuyos ejes están dados por la competitividad, la flexibilidad laboral, la producción de calidad y la globalización, que marcan nuevas relaciones con el espacio por parte de los habitantes y los trabajadores.
\end{abstract}

PalABRAS ClaVE: ciudad, campamento, cambio cultural, flexibilización laboral, patrimonio

Identity, Transformation and Patrimonial Rhetoric in a Mining City of Atacama Desert, Chile. This study derives from a synthesis and systematization effort, both in theoretical and analytical terms, regarding ethnographic material obtained during the last decade in the saltpetrous-rich city of María Elena, in the Atacama Desert, Chile. Identity formation, trajectories and experience of these city inhabitants, and the changes experienced by the settlement -a city conceived under the utopian tradition principles- are discussed. Emphasis is set on this settlement's transformation into a camp, and latter, towards an interest on the wealth-formation of the urban complex. This last form is observed as an expression of the changes experienced, which stem from the prevalence of a new model of accumulation, that in turn, has competitiveness, labour flexibility, quality production and globalization, as core elements, and that establish new relationships between inhabitants, workers and the territory.

KEYWORDS: city, cultural change, labour flex, labour flexibilization, mining camp, patrimony

\author{
JUAN CARLOS RodrígUEZ TORRENT: Universidad de Valparaíso, Chile \\ memoriasur@gmail.com \\ Pablo Miranda Bown: Pontificia Universidad Católica de Chile, Santiago, Chile \\ pmirandb@puc.cl \\ Desacatos, núm. 33, mayo-agosto 2010, pp. 151-166 \\ Recepción: 10 de diciembre de 2008 / Aceptación: 17 de abril de 2009
} * Proyecto del Fondo Nacional de Desarrollo Científico y Tecnológico (Fondecyt) 1060092: "María Elena, cambio y reestructuración cultural. Una car-
tografía antropológica de sus marcadores". 


\section{PRÓLOGO}

$\mathrm{E}$ l trabajo antropológico tiene como preocupación las relaciones sociales en un grupo, las que deben ser efectivas, representadas e instituidas (Augé, 2008: 11), y su coagulación es un modo de expresión de la identidad. La reflexión en torno a ésta apunta simultáneamente tanto a cuestiones íntimas en las que se juega la individualización como al horizonte de las configuraciones colectivas. En ambas dimensiones, la identidad da cuenta del significante de la diferencia específica; refiere a lo que subyace con cierta recurrencia y que singulariza, es decir, lo particular de cada uno o del colectivo a partir de las interacciones sociales y sus frecuencias diferenciales. Su posibilidad se constituye en cuanto existan elementos contrastivos o alter ego que operen como espejos que permiten completar la imagen del sujeto, lo que ofrece al menos dos respuestas preliminares: conciencia de quién se es y respuesta a de dónde se viene como dimensión filial y, a partir de ellas, ser reconocido en su trayectoria, desde la diferencia como manifestación de frontera. en una aproximación a la biografía individual y a los elementos que demarcan de manera activa o residual la memoria colectiva, siempre bajo el supuesto de la existencia de una desigual distribución social del conocimiento, que impone modos enunciativos dentro de los límites de una comunidad como expresión de la forma particular de recorrer, usar, marcar y experimentar el espacio. De este modo, si se trata de explorar las señas de la identidad de una comunidad, no hay ni puede haber pretensión de totalidad por parte del investigador, sino una fijación aproximativa de un conjunto de coordenadas dentro de las cuales se mueve o identifica la existencia, partiendo de las marcas heterogéneas que hablan de un conjunto de diferencias de género, edad, escolaridad, trabajo, lugar donde se habita y posición en la estructura social, en el marco de un espacio y tiempo definidos.

Entonces, a partir del registro, pueden observarse los distintos hitos que fijan el paso de los años, la relación con el pasado y sus sellos, lo perdido, lo relevado, lo querido, lo imprescindible, lo accesorio, los eventos traumáticos o el cambio. Por tanto, la mirada se vuelve sobre un espacio

que se manifiesta de manera crepuscular, móvil, fragmentario, escindido, sujeto a negociación con el presente, situado entre el recuerdo y el olvido, porque "el pasado siempre se practica en el presente" (Friedman, 1992: 23). Así, y tratándose de la relación que mantienen los sujetos con una ciudad que contiene su existencia, lo que está en juego es el vínculo que cada ciudadano posee con una u otra parte de ella, porque toda experiencia se asocia a recuerdos y significados que se expresan espacialmente (Lynch, 2008; De Certeau, 1999).

En el marco de este trabajo se desarrollan aspectos asociados a la identidad, la trayectoria, los cambios y experiencias de los habitantes de la ciudad minera de María Elena (1926), que fue construida de acuerdo con principios de la tradición utópica, en pleno desierto. Conceptualmente, se trata de una Company Town, cuyo conjunto urbano y complejo arquitectónico están plenamente integrados, con edificaciones destinadas a alojamiento (solteros, familias, obreros, técnicos, profesionales y extranjeros) y a servicios complementarios a los objetivos productivos, los cuales otorgan autonomía y suficiencia en un marco pre televisión y sin mercado interior. Hoy, a casi un siglo de su fundación, la ciudad constituye el último bastión de ocupación de la epopeya del salitre y del temprano capitalismo industrial, en el árido desierto de Atacama (Chile). Así, dos cuestiones preliminares marcan el interés en la ciudad de María Elena:

1) Su emplazamiento: ya que hablamos del desierto como paisaje y elemento contenedor de la vida que, como sostiene Fernando Martín, ofrece una peculiaridad: "allí no sobrevive lo que se experimenta y no es realmente eficiente; tampoco lo secundario es necesario". Porque éste "es un lugar de innovación y retorno a los propósitos primeros, donde el proyecto aparece desnudo, concreto, simple" (Martín Juez, 2007: 15).

2) Que como ciudad, fue inventada — en medio de la na$\mathrm{da}$ - con la lógica de los utopistas del siglo XIX, lo cual se constituye en un desafío teórico y práctico que crea la necesidad de ser altamente eficientes en el programa urbano y en el desarrollo de una convergencia de intereses y de formas asociativas, para que éstos se transformen en una cultura particular. 


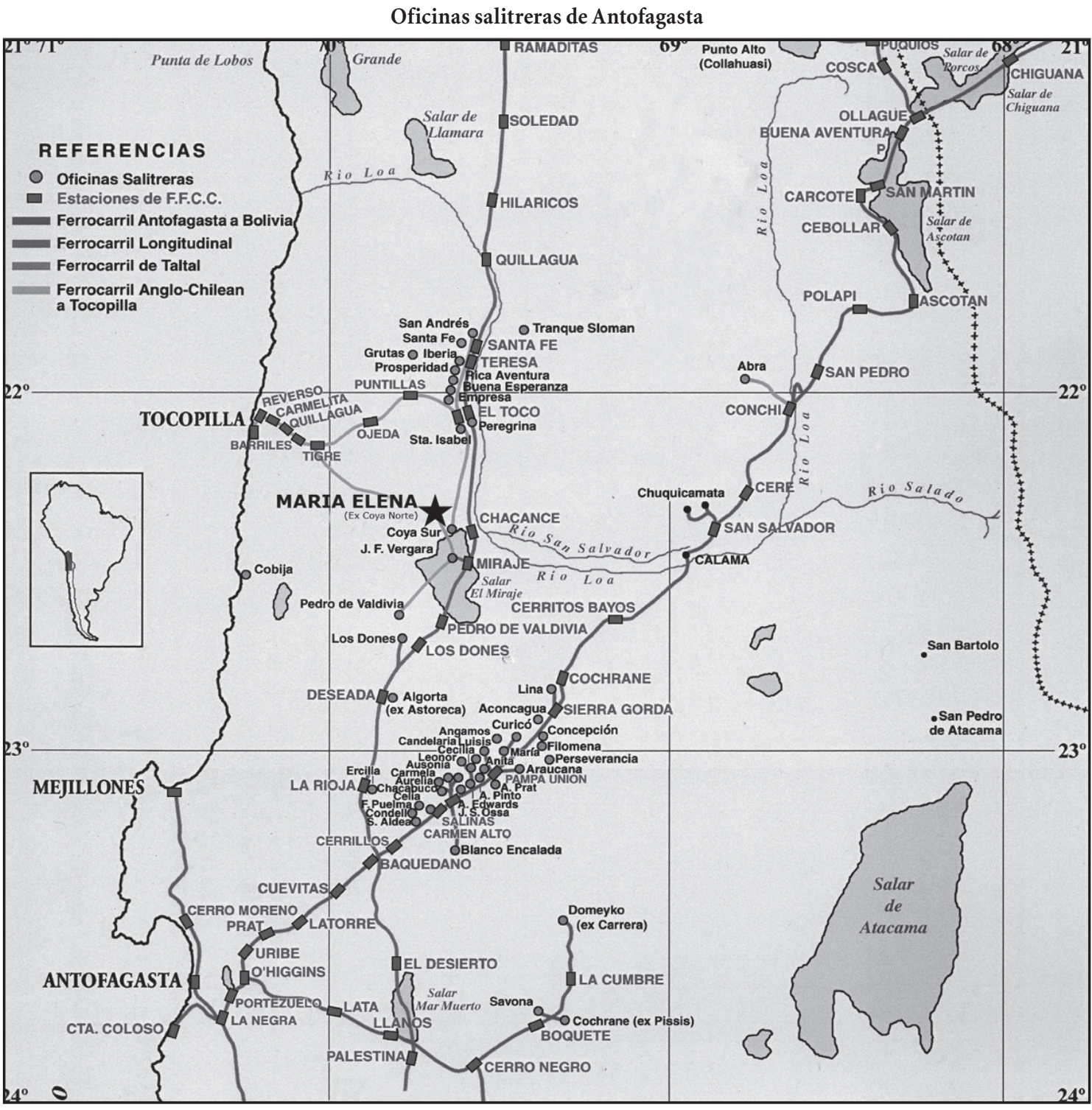

Fuente: Adaptado por los autores de Álbum Desierto, en línea: <http://www.albumdesierto.cl $>$.

Por tanto, se trata de un emplazamiento urbano construido de cara al desarrollo de la explotación del nitrato y la industria del salitre, como parte del capitalismo industrial. Es una ciudad atrapada hoy en medio de un gran cementerio de antiguas oficinas (asentamientos humanos) e inmuebles industriales, en su mayoría abandonados debido al aumento de los costes de explotación en la década de 1930 (véase Rodríguez, 2004); inventada e imaginada en el desierto que alguna vez el mismo SaintExupéry describió como el espacio "en el que siempre se está en medio". La concepción urbanística es total (instalaciones industriales, equipamientos y viviendas ligados 


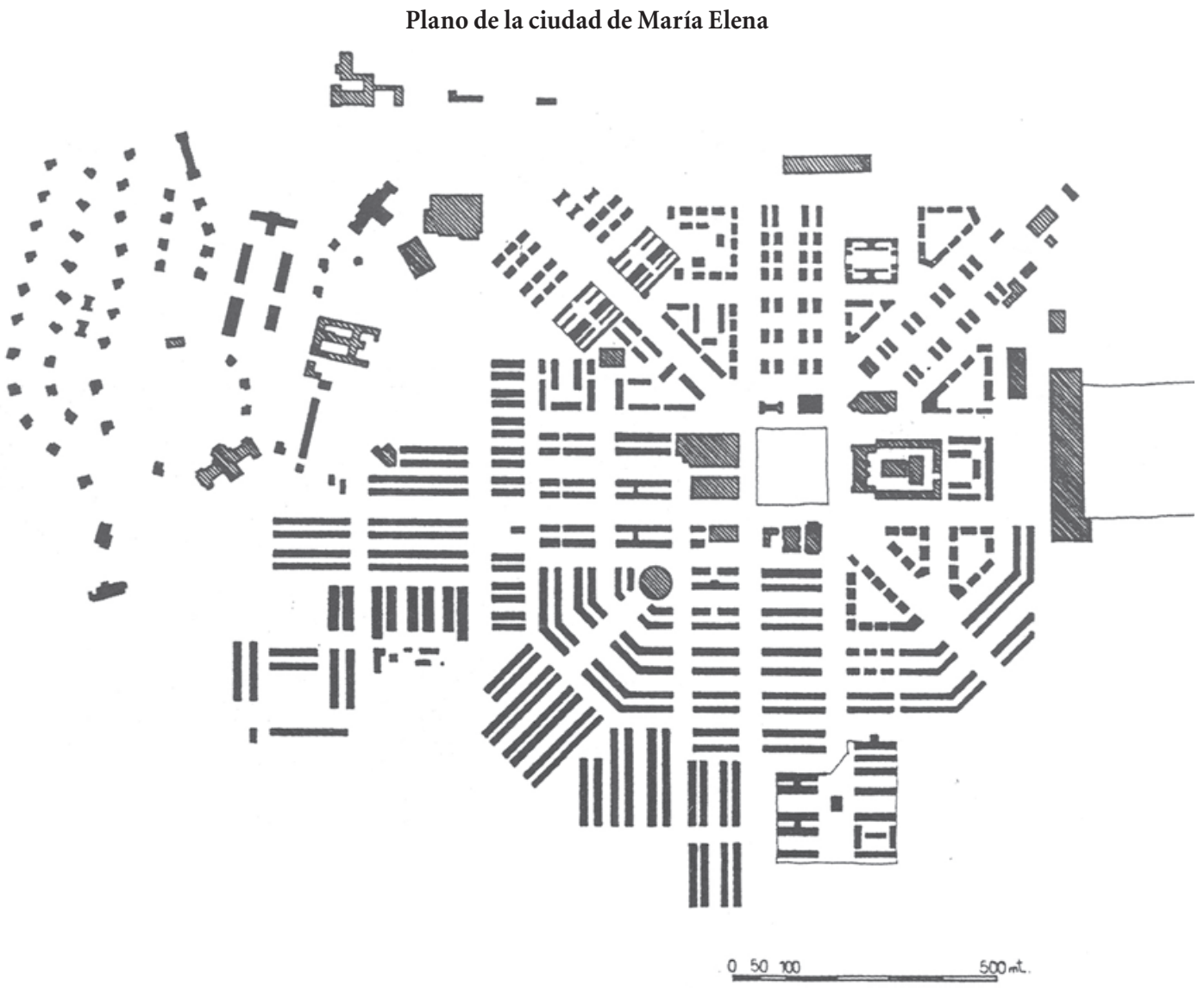

Fuente: Garcés, 1999.

a redes de ferrocarriles y puertos), destinada a albergar a más de 10000 almas, y su construcción se asocia con la necesidad de una nueva apropiación del desierto de Atacama, con nuevas formas productivas y tecnológicas que permiten trabajar con minerales de más baja ley; también influye el renovado interés por explotar la riqueza del sitio.

Desde el punto de vista humano, y de ahí la reflexión inicial sobre la identidad, la Compañía tuvo que desarrollar lineamientos que uniformaran ciertos patrones de conducta y relaciones, que crearan las bases de un sentimiento de pertenencia, lo que implica responsabilidad y expresa interacciones, valores, ideas, intereses y formas de pensar; esto se constituye — con el paso del tiempo — con aportes y visiones culturales provenientes de distintos lugares, regiones, paisajes y países. Muchos de los tempranos trabajadores eran ajenos a la lógica de la tradición industrial, ya que provenían de zonas agrícolas deprimidas.

Así, el caos de piedra y tierra ardiente que define a este desierto se convirtió en la base de la ciudad; pero, también, en símbolo de fe y esperanza. Su aislamiento, sin ser una ciudad de tradición indígena, es lo que permitió dar fuerza a la memoria colectiva y a la oralidad como patrón de sociabilidad y, de paso, observar la cultura como una totalidad de alto contraste con el resto del país, convergente a pesar de sus matices internos. 


\section{PRIMER ACTO: LA FORJA DE LA IDENTIDAD A PARTIR DE UN PROYECTO UTÓPICO DE OCUPACIÓNTERRITORIAL}

La ciudad de María Elena, desde el punto de vista social, se constituye en un gran atrapasueños. A ella llegan muchos que carecen de vivienda, trabajo estable y alimentación, que huyen de condiciones de pobreza. A estas múltiples identidades hay que darles no sólo trabajo, sino vivienda, alimentos, educación, salud, entretenimiento, servicios de electrificación y agua potable. En paralelo, es preciso disciplinar la diversidad no acostumbrada a criterios de empleabilidad industrial.

Más allá del paisaje que lo determina en su génesis, reconociendo la magnitud de lo propiamente infraestructural y arquitectónico del complejo utópico (véase Garcés, 1999), se trata de ordenar estratégicamente un universo multicultural y familiar en favor de un objetivo productivo, desde la elección del emplazamiento hasta la observación del más mínimo detalle ${ }^{1}$, en una ciudad que no les pertenece ni les pertenecerá a las personas, sino a la empresa minera; la cual, además, quiere transformar la iniciativa en un microcosmos coherente, funcional y sustentable económicamente, ya que toda empresa que invierte busca el lucro y ésta no es la excepción.

Desde el punto de vista humano, etnográfica y etnológicamente, observamos la constitución de lo que podemos llamar un sujeto entero. Es decir, hombres-trabajadores que pueden ser apreciados en su conformación por diversas relaciones sociales y referentes normativos, quienes hacen - junto con su familia - de todas las actividades extralaborales una extensión coherente con su trabajo. No es sólo el trabajador y lo que le corresponde hacer de acuerdo con el objetivo comprometido en su rol lo que se revela, sino que todo lo que él hace es coherente y consecuente con el objetivo de la forja de una comunidad y la efectividad de la ciudad.

Son los elementos propios del aislamiento, así como la diferenciación y el contraste interno y externo, los que

\footnotetext{
${ }^{1}$ Por ejemplo, dos redes de agua en las viviendas: una de agua dulce para cocinar y para el aseo personal, y otra salobre para el excusado.
}

constituirán un componente central en la perspectiva de la identidad que se forja durante décadas. Ello, por una parte, demanda una institucionalidad ad hoc, centralizada y panopcial, que marca como pieza de control las posibilidades de permanencia en la ciudad y de goce y usufructo de sus instalaciones y servicios; y, por otra, se estimula un universo conversacional con mucha autonomía, en el que todos sus habitantes pueden hablar de lo mismo - al modo de Anderson (2002) —. El acatamiento de la norma y el reglamento otorga metafóricamente el título de ciudadano y la posibilidad de permanecer y de constituir un proyecto vital para muchas generaciones; del mismo modo, la desviación es sancionada.

La instauración de la ciudad impone convertir lo heterogéneo cultural en homogéneo. Entonces, en concordancia con los objetivos productivos, encontramos el despliegue de un esfuerzo pedagógico empresarial de rasgos esencialmente protestantes — por su énfasis en el valor del trabajo- con el objetivo de asimilar y disciplinar a los hombres, mujeres y familias dentro de la lógica industrial y propiciar la integración expedita a un espacio social y cultural en construcción. Esta formación discursiva y simbólica se afianza y liga, para ser efectiva, a un espacio inicial de contención y de regulación del movimiento físico de la población, es decir, la ciudad vive una fronterización mental y material que se constituye como categoría divisoria, desarrollando un circuito de comunicación volcado sobre sí mismo, separado del exterior y disociado de la historia misma de la explotación del nitrato ${ }^{2}$, para que ésta pueda someterse a los nuevos imperativos empresariales en el marco de la llamada cultura Guggenheim ${ }^{3}$.

El objetivo se consumó en la medida en que la ciudad pudo ser autosuficiente. Es decir, el proyecto infraestructural y la concepción humana, expresados en un estilo de vida y de la mano de los objetivos productivos, pudieron mantenerse atractivos durante décadas, vigorosos y efi-

\footnotetext{
${ }^{2}$ Nos referimos a su ligazón con el movimiento obrero y al surgimiento de los partidos populares.

${ }^{3}$ Hablamos de cultura Guggenheim como expresión de la implementación de una nueva y moderna forma productiva, que permite operar con nitratos de más baja ley, contingentes de trabajadores que realizan menos esfuerzo físico y correlatos sociales que implican sistemas de protección social.
} 
cientes para contener dentro de sus márgenes a los trabajadores y las familias (Rodríguez, 2004, 2007). Lo importante aquí es que la fórmula de consolidación de la ciudad utópica, para ser viable, implica también una política de relaciones industriales modernas como producto histórico de la acción de los actores (capital-trabajo), cuestión que presupone como eje una política de pleno empleo para la población económicamente activa, y subsidiaria para quienes son dependientes (Rodríguez y Miranda, 2008).

Así, se forja un orden laboral que se traduce en un fuerte sentido de identificación, sustentado en la protección, lo que da paso a la lealtad y el sometimiento a dimensiones económicas, políticas, domésticas, familiares, recreativas, sociales y culturales, organizadas coherentemente como un todo y asociadas a un conjunto de valores éticos primordiales, como el "sentido del deber" para con la familia y el trabajo, la responsabilidad consigo mismo, con los demás y con el cuidado de los recursos, la maquinaria, las herramientas, la infraestructura industrial y la pública. En esta obediencia y este cuidado se inscriben "el pertenecer" a María Elena y "el estar" en María Elena (Rodríguez y Miranda, 2008).

Más allá de este caso etnográfico, entendemos que teórica y conceptualmente la homogeneización en los enclaves mineros es una cuestión vital para la generación de una "cohesión social" y para fortalecer una identidad, ya que las interacciones y la asociatividad se dan de manera siempre dual, tanto dentro como fuera del trabajo (Zapata, 2002). El objetivo homogeneizador de la multiculturalidad, que por cierto es aculturativo en relación con la identidad con que se llega, resulta coherente con la pretensión de sustentabilidad de una ciudad privada que se piensa y configura como "comunidad imaginada" (Anderson, 2002). Su estabilidad requiere de ritos que operen como catalizadores de esta lógica y, a la vez, como control del tiempo y el espacio, y de una cierta exultación de valores e ideales, que puedan operar como marcas de respeto y de refuerzo del lazo social para reafirmar las propias creencias (Maisonneuve, 2005: 12-13).

Son los ritos cotidianos (salir a comprar el pan, el hormigueo de personas que se forma a la salida de la escuela, el ir a practicar deporte, al cine, al teatro, al baile, a la alber- ca, al zócalo y a la glorieta) los que dan sostén al logos y, de paso, a una inteligibilidad de su orden estético desplegada en significados que se traducen en la memoria colectiva. Su delimitación espacial facilita el trabajo etnográfico y etnológico, pues todo habitante de edad avanzada que ha permanecido dentro de los límites de este universo conversacional, y que ha hecho su vida en la ciudad de manera ininterrumpida, mira con cierto barroquismo el acontecer temporal, y no deja espacios en blanco enfrentados a un mapa de la ciudad. La idealiza, la satura y, a la vez, la especifica, destacando detalles que el tiempo ha ocultado o borrado; recoge múltiples elementos que consolidan los márgenes y contornos de su imagen; la hace legible, eficaz, y la convierte en una entidad perfectamente separable, porque conoce también su microhistoria.

Escuchar hablar de la ciudad produce una extraordinaria fascinación. En mucho se trata de declamaciones en torno a lo ausente; se ofrece una belleza en la que aparecen los vivos, los fantasmas, sombras grises y figuras eclipsadas para dar fervorosa magia al pasado. Pero, ante todo, descuelga una idea central: el decantamiento de estas prácticas genera una importante diferenciación en relación con el país, ya que lo que se integra posee una matriz cultural estadounidense. Así, además, el estilo de vida, sustentado en la seguridad salarial, alimentaria y habitacional, refuerza la idea de la distinción positiva a favor de María Elena, inclusive al compararla con urbes importantes.

Se configura un mundo moderno en su expresión más radical: social, tecnológico y laboral. El proyecto se hace acompañar de sistemas de protección para la población, en salud, vivienda, alimentación, educación y previsión; nuevos procesos productivos, aplicaciones y regulaciones laborales, inscritas dentro de las políticas de Estado, que favorecen al trabajador. Metafóricamente, el engranaje de esta arquitectura configura una potente dualidad, que se constituye en una certeza básica: el antes y el ahora, nosotros y los otros, lo que inaugura la idea del "mejor de los mundos".

Reconociendo los antecedentes expuestos, se desprende que el proyecto de ciudad es de largo plazo, por lo que va de la mano con el proyecto de vida de quienes se comprometen con estas formas. Desde el punto de vista productivo, la explotación del nitrato se pone en marcha y se 


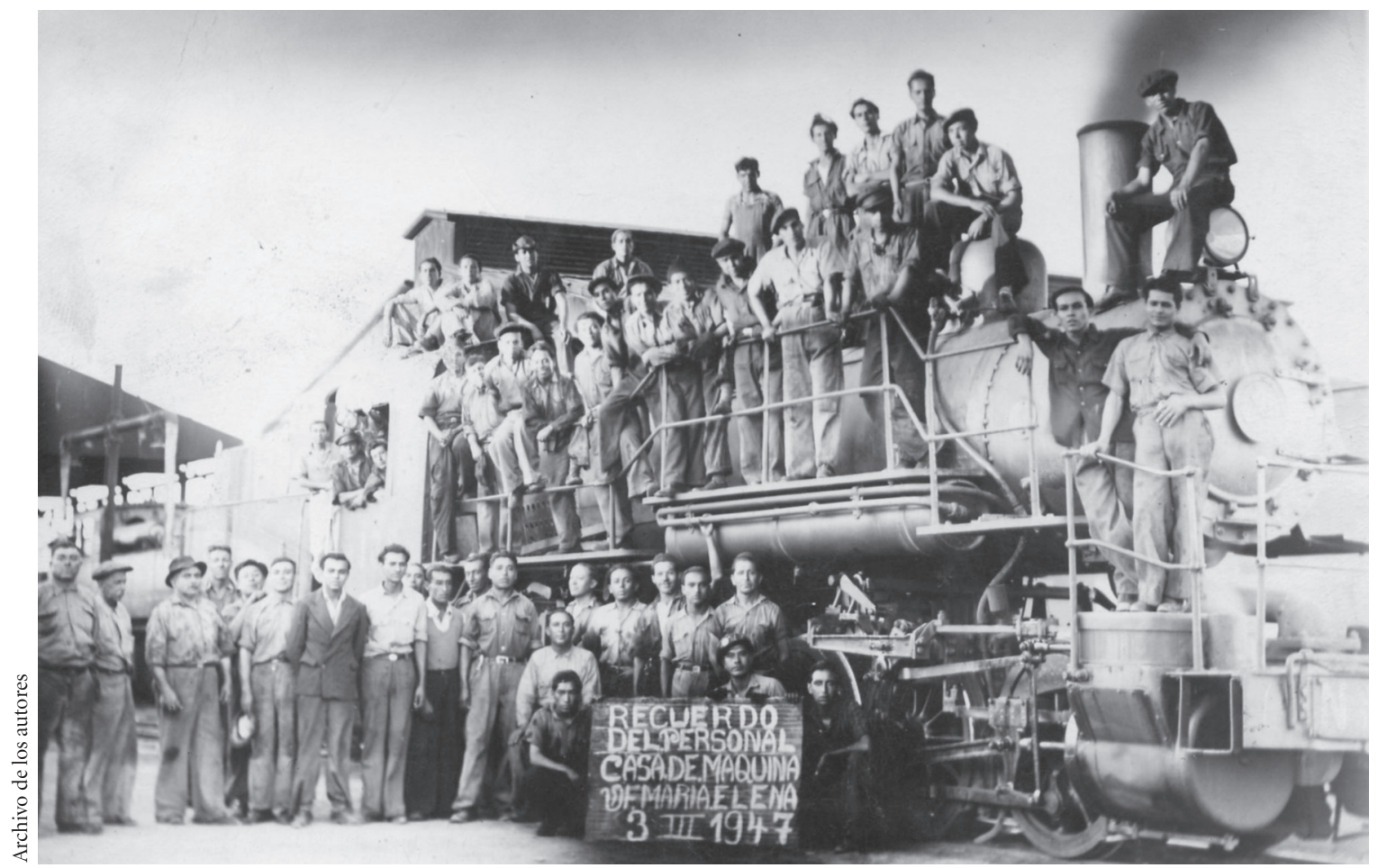

Imagen de la casa de máquinas y los trabajadores de la salitrera María Elena a mediados del siglo xx.

vuelve sustentable a partir de la internalización progresiva del conjunto de principios ético-normativos por parte de la población, lo que permite usufructuar y gozar de las instalaciones y servicios ofrecidos por la Compañía; asimismo, el trabajo como elemento integrador otorga una posición y una identidad de clase, y una identidad personal basada en su especialización, que se aquilatará en la idea del "pampino" (Rodríguez y Miranda, 2008).

Teóricamente, asistimos a la forja de un universo conversacional que goza de cierta autonomía. Lo importante es que se transforma en "un escenario físico vívido e integrado, capaz de generar una imagen nítida, [por lo que] desempeña asimismo una función social. Puede proporcionar la materia prima para los símbolos y recuerdos colectivos de comunicación del grupo" (Lynch, 1998: 13). La rigidez de los límites y las obligaciones del contrato colectivo se vuelven antecedentes superlativos a la hora de mirar la trayectoria de la ciudad y los habitantes de María Elena. Cuando el habitante resalta la continuidad de su traza, las diferenciaciones sociales asociadas a barrios, la existencia de un solo centro que hace del caminar una acción convergente, y que todos los puntos nodales son conocidos, los símbolos generales se vuelven vigorosos.

$\mathrm{Al}$ ver la fórmula utópica en perspectiva, queda demostrado cómo las instituciones — con el tiempo- "crean comportamientos y culturas", por lo que hay "usuarios" $\mathrm{y}$ "defensores" de las mismas (Lucena, 2006: 210). Desde ahí aparece la ciudad bella, la arrogante, la amistosa, la idea de Paraíso, la protectora. Todo lo que se requería en términos de servicios estaba disponible dentro de los márgenes de la ciudad, inclusive aquello que excedía a la satisfacción de las necesidades básicas. La conexión y el intercambio con las otras oficinas del entorno, que constituían el alter ego (véase mapa de las oficinas salitreras), estaban dados por relaciones empresariales, deportivas y familiares.

Antropológicamente, la vertebración de los elementos que van avalando este proyecto de tipo pedagógico y ritual 
es de amplio espectro y afecta cuestiones sociológicas (acción social), de derecho (orden normativo), psicológicas (conductas), educación (hábitos y actitudes) y económicas (consumo). Por ejemplo, al principio se expresa en llamadas de atención sistemáticas, acompañadas de cuadros estadísticos que indican cuestiones relativas a la tasa de accidentes laborales, a las horas perdidas en las faenas y la productividad, para, más tarde, pasar a juicios de valor sobre los hábitos y conductas de algunos de sus habitantes, reforzar cuál es el comportamiento esperado y resaltar con intensidad las hazañas y glorias deportivas locales.

En términos diacrónicos, la alimentación subsidiada, el vestuario de fácil acceso y los mecanismos de ascenso laboral, desconocidos en general en el país y por los propios obreros del salitre, es lo que favorece el asentamiento de bases estructurantes de la vida colectiva, ayudando a armonizar, contener y conducir durante décadas las expectativas de los habitantes, lo que se expresa en códigos escritos (distintos reglamentos) y principios de uso social, tanto en las interacciones generales como intrafamiliares. establece de manera superlativa la eficiencia y la vida sustentada en este proyecto utópico.

Entonces, en el ars memoriae de sus viejos habitantes hay un espectáculo que procura la imagen de la propia existencia. Esto significa la apreciación de un reparto morfológico de la existencia en ese espacio, en el que la ciudad sólo puede ser contada, narrada y compartida porque "yo estuve ahî". Por tanto, hay una gramática cuya sintaxis sólo es conocida por los hombres y mujeres que dieron forma a ese universo conversacional; gramática que testifica los hechos arcaicos y recientes como los contornos de la diferenciación interna.

En función del conjunto de los satisfactores detallados que registra el trabajo de campo, todo cambio morfológico, espacial, laboral, social, cultural es sentido como la corrupción del límite o la pérdida de la confianza básica. La alteración, por ínfima que sea, se constituye en el momento de toma de conciencia del lugar ocupado durante décadas, de la estabilidad de las estructuras y de cuanto se disponía.

\section{SEGUNDO ACTO: LA CIUDAD ABIERTA. DE LA PROTECCIÓN A LA PRIVATIZACIÓN}

La claridad y fuerza de este ejercicio y del aprendizaje pedagógico de construcción de un tipo de ciudadano que se encuentre, en lo posible, desafectado de lo que acontece en el exterior (contradicciones entre capital y trabajo, movimiento social y Guerra Fría) y que reconozca los ingentes esfuerzos que hace la Compañía para que él goce junto a su familia de altos estándares de bienestar, es lo que decanta en sus actores la identificación y el compromiso con la ciudad, los cuales pasan a ser extensivos respecto de la Compañía como empleadora. Así, se constituye una "comunidad de destino" que se decanta en una cultura del desierto; pero es la misma seguridad la que se transforma en "pasividad" a la hora de imaginar otros escenarios.

Sabemos que el movimiento caracteriza a la cultura y ninguna comunidad puede prescindir de él. La privatización de la Compañía, en $1988^{4}$, puso fin a la pretensión civilizatoria original. Con ello se revelan dos cuestiones de una empresa que quiere ser moderna, eficiente e internacionalizada: la no sustentabilidad económica de un proyecto que implica subsidiar a personas no ligadas a faenas $\mathrm{o}$ a sus necesidades productivas, y la introducción de criterios ambientales y legales relacionados con indicadores de salud y calidad de vida.

Estos temas impactan sobre las certezas básicas y la inacción de la población cautiva. Con ello, la ciudad se abre al exterior de manera nunca vista para sus habitantes, por lo que el nuevo contraste se constituye en un rasgo inédito dentro de los marcos de una urbe que era sentida como propia y dominada física y psicológicamente por toda la población, aunque nada les pertenecía.

\footnotetext{
${ }^{4}$ Las distintas administraciones corresponden a la Compañía Salitrera Anglo Lautaro - de capitales estadounidenses-, la cual se convierte en sociedad mixta con el Estado de Chile - a través de la Corporación de Fomento a la Producción (Corfo) — en mayo de 1968 (62.5\% de participación frente a $37.5 \%$ ). En 1970, la Corfo asume el control de la Compañía con 51\% de participación, la cual llega en el mismo año a 70\%. En 1971, el Estado de Chile logra 100\% del control y luego la privatiza en 1988 .
} 


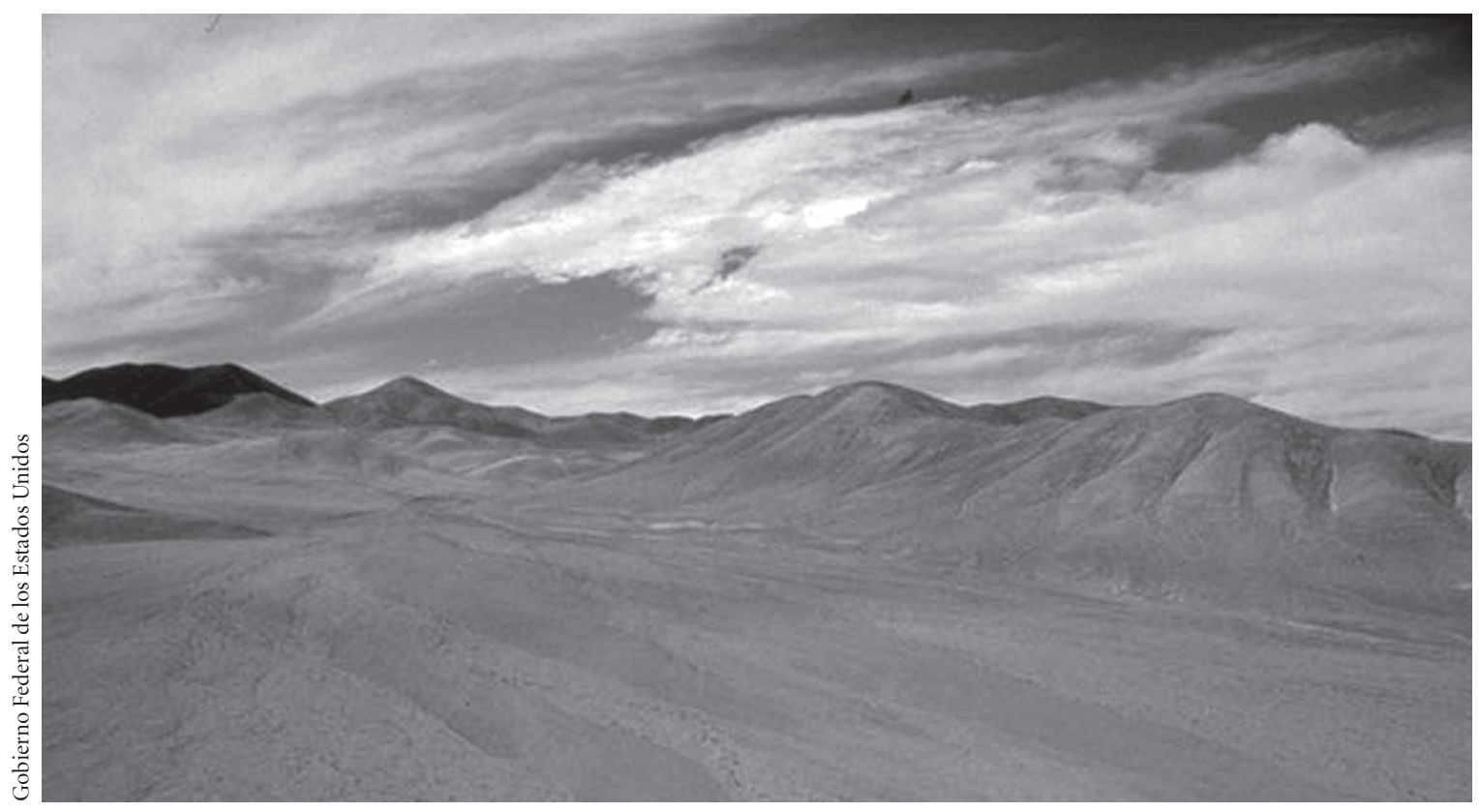

Desierto de Atacama, ubicado en el norte de Chile.

Se producen importantes reajustes laborales y existenciales, tanto en la plantilla de trabajadores (aparición de la idea de flexibilidad numérica y funcional de la misma), como en las prestaciones sociales históricas (pulpería y productos básicos) y en los servicios subsidiados (agua, luz eléctrica, vivienda), así como una no menor reestructuración del estilo de vida (desaparición del deporte y la recreación), de las formas de reproducción social y biológica (socialización para el trabajo local y proyecto vital) y de la representación que tenían los habitantes de sí mismos, en la medida en que la ciudad se debe abrir demográficamente a un amplio espectro de nuevos trabajadores provenientes del exterior de la pampa, con distintas calificaciones, otras experiencias laborales, historias e identidades, lo que renueva las formas de relación, los lazos sociales y las orientaciones sobre las que descansa la sociabilidad.

De manera cada vez más acelerada aparecen la figura del riesgo (Beck, 1998; Giddens, 1994), la inseguridad y la desconfianza, que habían estado ausentes. La entrada de los nuevos actores alerta y da cuenta de la prescindencia de muchos de los viejos habitantes y trabajadores históricos, como un rasgo nuevo para éstos y sus familias. Su presencia trae consigo un reordenamiento de las claves de la autenticidad; se da paso a la adopción inevitable de otros elementos significantes foráneos, traídos por los innumerables trabajadores tercerizados de las empresas contratistas y reforzados a través de la masificación de la televisión satelital. Esto revela varias cuestiones: la ausencia de un sujeto político local que no requería de institucionalización; la gran diferenciación cultural con su matriz extranjera; la reestructuración de la estratificación interna; la instauración de un código tecnológico que no se domina. A esto se suma, como cuestión no menos importante, la percepción del evidente deterioro material de la ciudad.

En sentido estricto, la homogeneidad social y cultural ya no es un requisito para la sustentabilidad de un proyecto económico productivo anclado en redes globales (Bauman, 2006). La uniformidad discursiva, que forjó la conciencia de un "nosotros", se ve sobrepasada y no es ya fundamento para la productividad eficiente de una compañía como lo fue en el pasado, por lo que se enfrenta un proceso aculturativo cuyo eje está dado por la penetración de la figura de un campamento en una ciudad. El desa- 
rrollo estratégico de este proyecto minero y de otros de la misma especie se allana con la diversidad cultural y la calificación de quienes se vinculan con la empresa y la ciudad a través de servicios de subcontratación; en particular, los trabajadores externos se encuentran disociados de toda la experiencia de la vida de las familias pampinas y la comunidad.

La empresa SQM, propietaria del complejo urbano, al restringir y eliminar muchos de los beneficios históricos, hace que las familias se percaten y tomen conciencia de que nada les pertenecía. Por tanto, se debilita el patrón estructurante de la vida colectiva y se pone fin a la idea del proyecto vital en María Elena, porque ya no son necesarios los viejos, los niños ni las mascotas. Asimismo, se erosionan los rasgos homogéneos de la cultura y se fractura el universo conversacional; ahora, todos los antiguos son prescindibles en la medida en que no se ajusten a la nueva racionalidad, y muchos relatos son posibles. Hay una necesidad de replantearse el mundo y el "sí mismo" dentro del mundo, y renovar las ganas de vivir sin la seguridad del paraíso en el que se habitó durante décadas.

El impacto es irreversible, ya que afecta tres elementos nucleares de la cultura: trabajo, familia y espacio. De ahí que los actores afectados cubran un amplio espectro: trabajadores que son desafiliados por su calificación; jóvenes y niños que tienen más espejos en los cuales mirarse, lo cual amplía el horizonte de sus expectativas, y que creen definitivamente que su vida está en otro lado; adultos mayores que no tienen lugar cuando la relación con el espacio local se vuelca sólo al trabajo, ya que la vida subsidiada desaparece; trabajadores que operan con sistemas de turnos con residencia familiar en otras ciudades, y que son integrados sin distinciones a la vida cívica del país; y el vivir para producir y no para residir en María Elena.

Interiormente, el proceso aculturativo modifica el relato de la ciudad segura y sin riesgo de antaño. La presencia de trabajadores tercerizados, temporales y sin familia, ayuda a acentuar una discontinuidad de la visión colectiva del espacio y de los barrios, al usar viviendas antes consagradas al goce familiar, al punto de que se ha alcanzado un índice de masculinidad de 1.32. Así, la uniforme mitología de la identidad se ve alterada en sus relatos, aparecen lecturas sobre los peligros, aumenta la desconfianza, sur-

\section{Gráfica 1. Evolución histórica poblacional de María Elena}

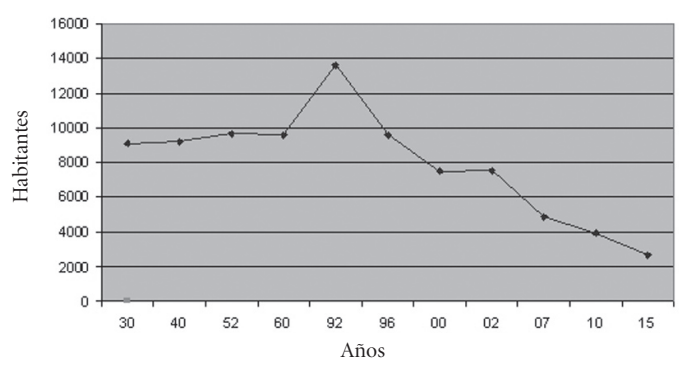

Fuente: Elaboración propia.

gen las angustias, se resquebrajan las certezas y se renuevan las ideas sobre "sí mismo" en el marco de una nueva estratificación. Exteriormente, como contrapunto a esta condición, se resaltan dos aspectos: "los que salimos de María Elena [en el marco de la cultura extranjera], casi todos somos profesionales [...] los que se quedaron, son los más pobres".

Se trata de una diversidad que irrumpe y se impone sobre la armonía cultural. Este proceso aculturativo sólo es comprensible apoyándose en el marco de las macro transformaciones instaladas en el mundo del trabajo: derecho laboral, localización laboral, horario laboral. Ahora existen formas plurales de sistemas de turnos, contratación y subempleo, especialización que se constituye como modo estandarizado de razonamiento de la empresa (Linhart, 2007: 26; Iranzo y Leite, 2006). Esto, leído como la entrada de un campamento minero en una ciudad, despliega la necesidad estratégica de una mayor eficiencia en el uso compacto de todas las instalaciones del complejo arquitectónico con criterios diversos, como la flexibilidad, la funcionalidad y la intensidad, y con formas parciales y prolongadas, de modo que puedan acoger a las diversidades laborales, históricas y no históricas. Así, se redestinan los usos de muchas de las viviendas familiares, lo que acelera la salida y la desafiliación de los tradicionales grupos familiares de María Elena, ya que hoy el trabajo y los objetivos productivos tienen autonomía en relación con habitar la ciudad.

Lo señalado hasta aquí tiene un fuerte impacto en términos demográficos, como se puede apreciar en la grá- 
fica 1, la cual nos indica tanto el comportamiento histórico de la población como las proyecciones futuras a partir de lo que ha significado el fin del pleno empleo y la implementación de sistemas de turnos y de subcontratación, y en la medida en que ya no existe relación entre trabajar en o para la compañía minera y habitar la ciudad de manera permanente, como en el pasado. Es otro de los rasgos aculturativos derivados de la modernización laboral, se reduce el número de familias y comienza un proceso acelerado de recambio de sus habitantes, con entradas y salidas —regulares o intermitentes— de los actores ${ }^{5}$.

A partir de las cifras indicadas en la gráfica 1, en la caída y proyección de la población debemos reconocer una fractura respecto de la necesidad fundacional del modelo de la Company Town, asociada al pleno empleo, y el paso a formas flexibles de empleabilidad. Axiológicamente, cuando la población comienza el tránsito de la seguridad a la inseguridad, los impactos se hacen sentir en lo doméstico familiar y en el pequeño comercio —que se vuelve insostenible-; se consolida una acelerada individuación a través del trabajo y una secularización de las esferas a las cuales el trabajador se encontraba integrado, lo que modifica los lazos sociales. Se alteran sustancialmente los tipos de interacción social y las formas de ocupación del espacio y la infraestructura, y se fragmenta así la unidad de visión a la que apuntaba Zapata $(2002)^{6}$. Esto se traduce en un abanico muy heterogéneo de afectos, certezas y juicios sobre la condición de la ciudad, a la que contribuyen tanto los foráneos como los locales que empiezan a vivir un proceso de marginalización, tanto psicológica como laboral, y por el cual demandan, como víctimas, la restitución de la ciudad antigua.

El conjunto de cambios puede apreciarse en la gráfica 2 (p. 162), en la que se indican las distintas relaciones de

\footnotetext{
${ }^{5}$ Tan sólo desde el punto de vista de la matrícula escolar, hay una disminución de unos 5500 alumnos en 1990 a unos 1500 en 2006.

${ }^{6}$ La flexibilización laboral permite compensar sin dificultad y rápidamente el proceso de desvalorización y obsolescencia del conocimiento de los trabajadores antes anclados a María Elena, lo cual estimula la recurrente renovación de la población y la circulación de nuevas habilidades provenientes de distintos lugares, con lo que se debilitan los compromisos con los compañeros, la ciudad, el espacio y el lugar.
}

tiempo y espacio que se mantienen con la ciudad. También permite visualizar la diversidad de actores, su atomización y la dificultad de las microhistorias para interactuar entre sí, en la medida en que se configuran anillos laborales inconexos y volcados sobre sí mismos, con rutinas desconocidas y, en su gran mayoría, impermeables para otros. No hay un genérico "trabajadores", lo que hay son formatos laborales distintos, con prácticas y estatus diferenciados que no constituyen un sujeto colectivo.

La gráfica 2 indica cierta inmovilidad de algunas familias pampinas en el centro, aquellas que han logrado ajustarse o sobrevivir laboralmente en la ciudad, penetrada por la figura de un campamento; otras, formadas en general por personas mayores, están desprotegidas y dependen cada vez más de algún tipo de subsidio, porque no tienen cabida en este esquema laboral de alta eficiencia integrado a redes globales. Sin embargo, la gráfica nos muestra, en su conjunto, un amplio movimiento de sujetos: los trabajadores tercerizados que entran y salen; los distintos sistemas de turnos que implican sólo el trabajo y la utilización de infraestructura de hotelería (dormir y comer) sin relación con la ciudad; los profesores que abandonan la ciudad-campamento cada día viernes para ir a "sus casas", lo mismo que la burocracia municipal; los adolescentes que piensan que su vida está en otro lugar y que se distancian irremediablemente de la ciudad-campamento.

Se enfrenta la coexistencia de distintas tradiciones laborales, siendo la histórica muy residual a la lógica imperante y, en algunos casos, no tiene conciencia global del proceso de internacionalización de la Compañía. Pero, además, es marginal en cuanto a que la empresa podría operar prescindiendo de ellos y su memoria "minera salitrera" desarrollada al alero del temprano capitalismo industrial. Físicamente, gran parte de los trabajadores pueden estar en la ciudad, pero laboralmente están aislados en un auténtico campamento que los hace indistinguibles de otros trabajadores mineros que, inclusive, son o pueden ser de otros ambientes, regiones o países, en la medida en que pernoctan en campamentos-hoteles que sólo se distinguen en la forma, pero no en el funcionamiento.

Por ello, en esta filosofía del trabajo requieren especial atención los trabajadores de la empresa que operan bajo la modalidad de sistemas de turno. Esta práctica funciona 
Gráfica 2. Movimiento de la población

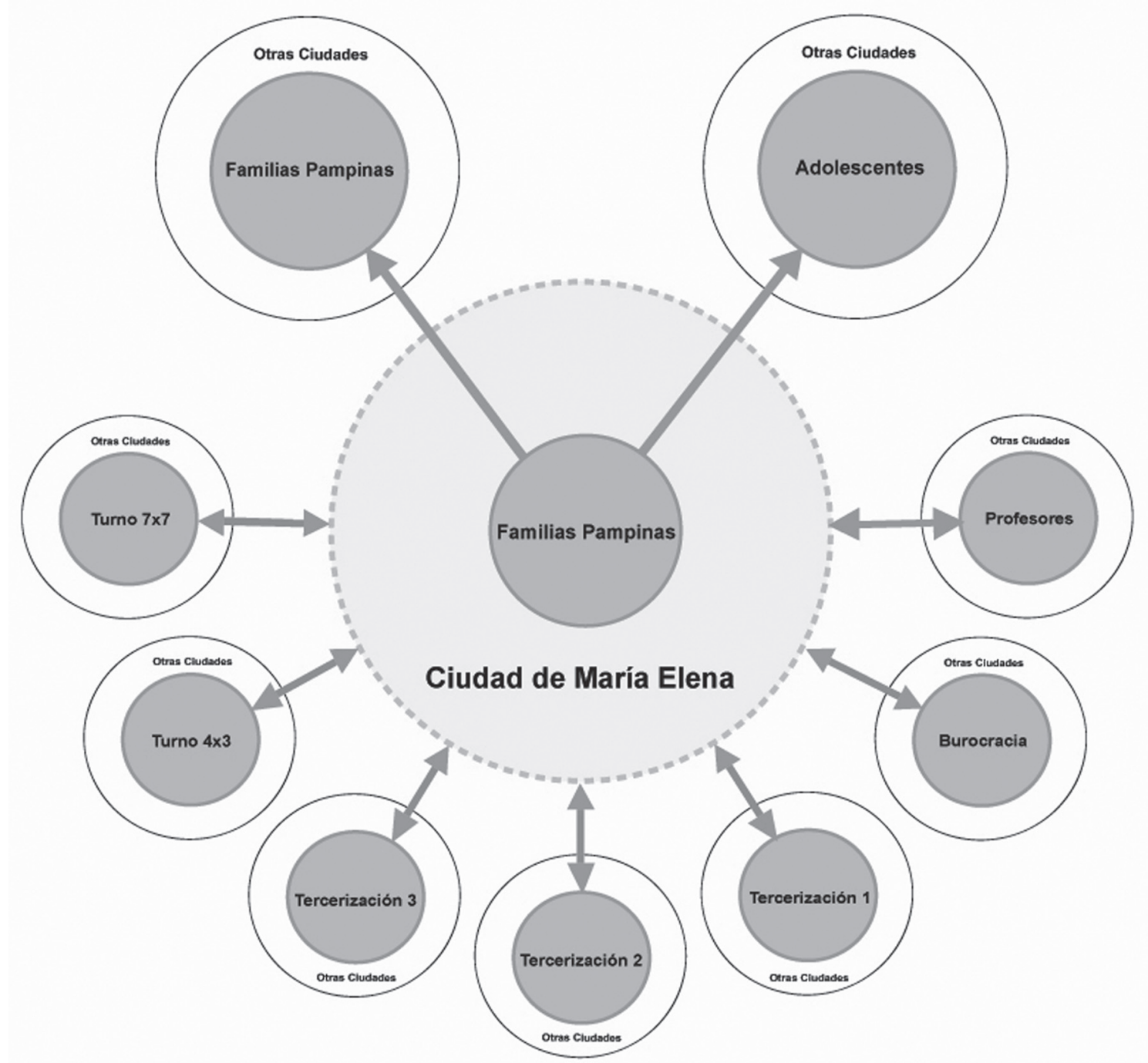

Fuente: Elaboración propia.

bajo el criterio de all inclusive, ya que reciben atenciones completas tanto en lo alimentario como en el alojamiento durante los días que dura su actividad, y alcanzan, desde el punto de vista de la calidad de vida, un nivel superior en relación con quienes aún permanecen en la ciudadcampamento. Esta condición residencial dentro de la ciudad, pero al margen de ésta, altera la relación con la urbe en la medida en que se invisibilizan, no la marcan y generan — para todos los efectos_ - una sociabilidad al margen de ella.

En medio de este modelo de reconversión del pleno empleo en la subcontratación, puede observarse que es sólo en el centro donde habita la memoria de los hombres, mujeres, ancianos y familias pampinas que aún viven en 
María Elena, los cuales son los depositarios de la vida colectiva de la ciudad y de la pampa y, paradójicamente, cada vez en forma más intensa, se encuentran al margen de lo laboral y tienen una exigua vida social. Otra parte de la memoria ya se la han llevado aquellos que se han ido. Pero también, en justicia, la penetración del campamento en la ciudad configura una memoria en curso que se mueve en los intersticios de lo laboral y que se destaca por su deslocalización física.

Si se trata de la ciudad y la idea de ciudad que puede registrarse a través de la oralidad, en gran parte ésta queda atrapada en ese centro, pero penetrada por mundos circundantes y por la corrosión de las certidumbres. Existen muchos más habitantes que los que se pueden contar y ver. Aquellos que la han experimentado y vivido durante décadas se quedan sin formas de protección, sin reconocimiento de las antiguas formas productivas de las que formaron parte, con un sentimiento vital y permanente de inseguridad, con una forma de enfrentar el trabajo que no permite la cohesión comunitaria. Todo esto implica que no hay capacidad de respuesta política ni organización posible, ya que cada vez hay menos iguales.

De este modo, etnográfica y etnológicamente, el proceso aculturativo altera las funciones básicas de la tradición, y cuestiona el carácter normativo de su condición legitimadora, identificativa y hermenéutica. Es decir, todo el background desde el cual brota el sentido de las acciones y expresiones posibles de esa cultura minera. Así, el proceso aculturativo que impone la modernización laboral hace que la morada se convierta en un "hábitat móvil, una forma de vivir el tiempo y el espacio no como si fueran estructuras fijas y cerradas, sino como fuentes que incitan a una apertura crítica", en el que se juega el sentido de la identidad, del lugar y de la pertenencia (Chambers, 1994: 18).

\section{TERCER ACTO: LA CIUDAD PATRIMONIALIZADA}

En los apartados precedentes hemos observado y destacado los elementos más importantes de un proceso aculturativo que traza la transición de la ciudad utópica a un campamento minero. Por cierto, la nueva figura no está exenta de problemas que demandan resolución, especialmente en lo que se refiere a la reestructuración irremediable del proyecto vital; pero, aun cuando en toda ciudad la percepción no es continua, sino fragmentaria (Lynch, 2008; Lindón, 2007; Hiernaux, 2007), la condición específica de la ciudad utópica y sus límites, definidos especialmente por la regulación social y el paisaje desértico que demarca el asentamiento, es también lo que impide nuevas pautas de actividad económica. Asimismo, hemos sostenido que esta imagen se debilita con la irrupción de los trabajadores tercerizados y los sistemas de turnos. Sin embargo, emerge de esta dinámica una tercera ciudad: la ciudad patrimonial, la ciudad que hay que ver, la que se puede mostrar y quizá la que hay que salvar, condición precipitada por un fuerte terremoto que la asoló en el año 2007, y que introdujo un violento e inesperado eje a las variables sociales analizadas como parte de esa transición y de las cuales depende el futuro de la ciudad minera como complejo urbano y de algunos de sus habitantes. Casi 80\% de las construcciones sufrieron serios daños y aproximadamente 300 casas quedaron inhabitables.

Entonces, como ciudad única por sus características inicialmente utópicas pero, sobre todo, por ser representativa del capitalismo industrial, la cuestión es cómo manejar el deterioro provocado por el sismo ${ }^{7}$ y, a la vez, consolidar la política de transformación de la ciudad a campamento, siempre en relación con el objetivo empresarial. En este sentido se abre un nuevo flanco de discusión antropológica respecto del tipo de relaciones que es posible esperar con esta aceleración, en el marco de un proceso de conversión. Se instala el qué proteger, con qué objetivo y con qué mirada, aun cuando el evento no hace sino reforzar la experiencia de convivir con la ruina a la cual se habían acostumbrado los habitantes. Ruina salitrera y minera, en la medida en que la política de la empresa dueña del pueblo desincentivó la inyección de recursos en la manutención de la infraestructura comu-

\footnotetext{
${ }^{7}$ El sismo afectó tanto a las familias residentes como a las instalaciones donde pernoctan trabajadores tercerizados y de la propia empresa, que operan bajo el sistema de turnos.
} 


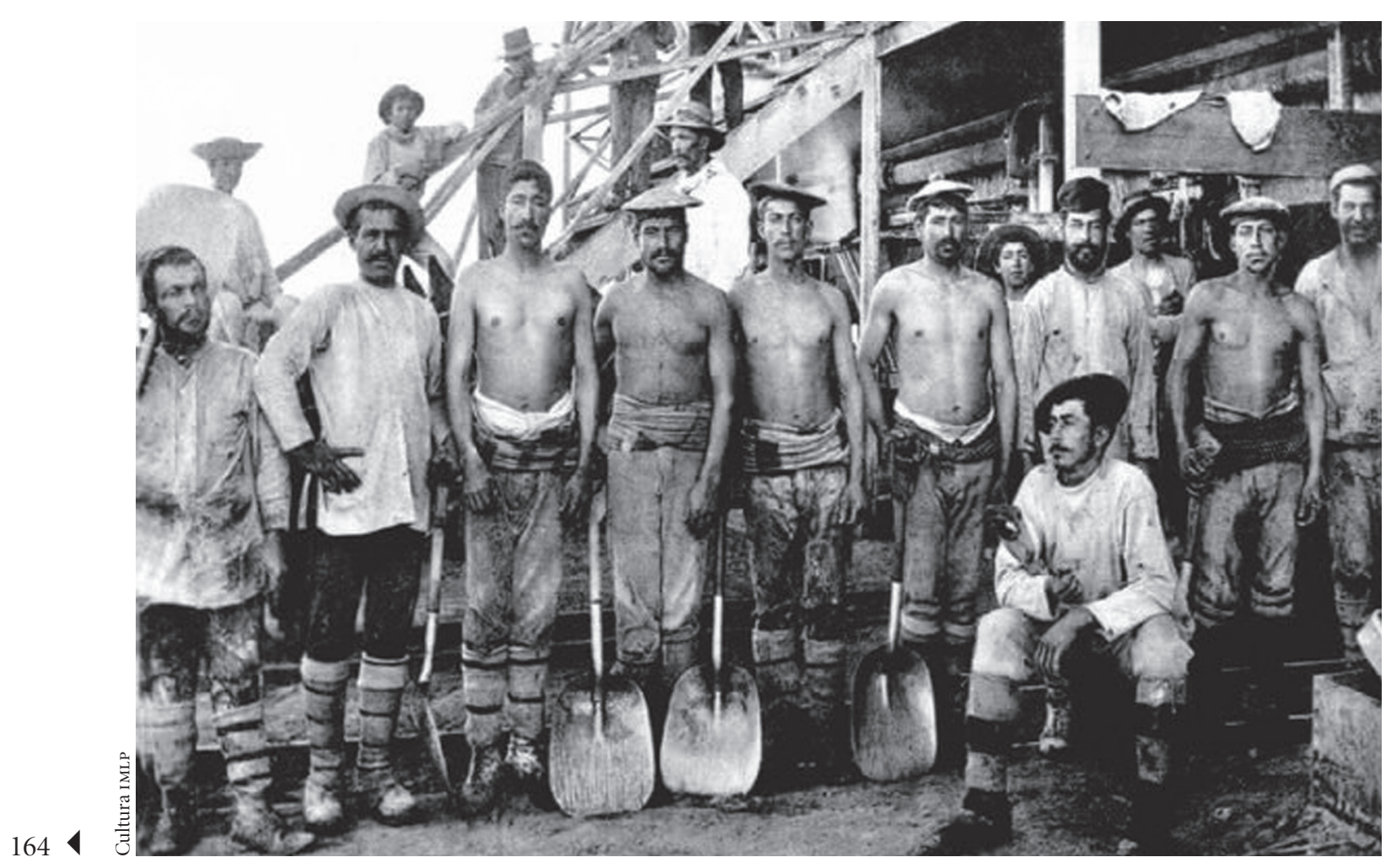

Trabajadores del salitre en Chile en los inicios del siglo XX, s/f, <http://culturaimlp.blogspot.com/2007_08_01_archive.html>.

nitaria (pintar, reparar) y en los subsidios (goce de vivienda y liberación de importe de luz y agua potable) para arrastrar la ciudad a su condición mínima de funcionamiento, con el fin de cumplir con sus objetivos productivos.

La ciudad y sus habitantes, como la ciudad para sus habitantes, sólo eran importantes en tanto que funcionales para el lucro, criterio que se modifica en cuanto la tecnología inaugura nuevos mundos que marginan a los trabajadores y la infraestructura caminera permite desplazamientos fáciles y expeditos, acordes con la flexibilidad laboral. En este sentido, debemos discutir sobre el patrimonio. Éste corresponde a una imagen que permite que los ciudadanos tengan cierto sentido de continuidad, de una trayectoria en común. Es decir, el patrimonio es la extensión de uno mismo o lo que está más allá de uno (los objetos y bienes), pero como bien común, como legado de aquello que se reconoce como propio. Nos indica que hubo otros antes que $y o$, que me legaron una cierta experien- cia, que habrá otros que me sucederán, y ese enlace particular da cuenta de la identidad y la articulación entre generaciones. Por tanto, no se trata sólo del pasado, también del futuro, de la mediación de lo que se resume o asume como propio; de una relación espacial con aquello donde se realizan las prácticas fundamentales y recurrentes de una comunidad.

De este modo, enfrentado el proceso de conciliación ciudad-campamento y ciudad-campamento-patrimonio, lo que llamamos patrimonio es huella, es experiencia de vida expresada en cartografía y puntos nodales con los que estamos familiarizados. Es, también, memoria individual y colectiva; una representación del tiempo en la que la experiencia personal se liga con la estructura de su sociedad, pues con la memoria se recuperan los eventos a través de distintos soportes, se instauran presentes relativos, formas de diálogo, redes de sitios y relaciones de pasados inconclusos, provisionales, discutidos y discuti- 
bles, referenciales al tiempo vivido y no vivido (Rodríguez, Miranda y Mege, 2002).

Entonces, con la patrimonialización como acción social y política, ¿qué pasado se quiere traer o recuperar?, ¿a qué memoria se quiere dar paso?, ¿a la histórica?, ¿mítica?, ¿utópica?, ¿arqueológica? Por ende, independientemente de estas memorias como recuperaciones, lo seguro es que con el rescate de algunos bienes inmuebles que corresponden al entorno de la plaza y los lugares inmediatamente adyacentes se da paso a un proceso de remitologización de la ciudad y a una ruptura — como sostiene Jameson (1991) — de nuestra experiencia tradicional de la temporalidad.

Aquí, por cierto, enfrentamos dos cuestiones problemáticas a las cuales se debe poner atención. Por una parte, la protección de la herencia del pasado frente a la cultura viva y, por otra, como extensión de esta fórmula, el posible paso al pastiche insulso, en la medida en que se impone la recuperación como subsidiaria de una tergiversación del pasado y sus vicisitudes, pues la cultura mítica y épica es residual.

La reflexión es importante, ya que lo que caracteriza a la ciudad-campamento es el desvanecimiento de su memoria en un nuevo régimen laboral que transforma a la ciudad en dormitorio u hotel, y la ausencia, como posibilidad, de un proyecto vital para las familias que sobreviven a los cambios. Asimismo, si se trata de recuperar para mostrar, más que para vivir, los marcadores seleccionados nos abren paso a la captura ciertamente "exótica del otro" que ya no existe, a través de la cámara y la detención del tiempo (véase Sontag, 2006).

De este modo, la ciudad patrimonializada, o el interés por patrimonializarla, es también un recurso por estetizarla. Así, nos habla de dos cuestiones que es menester diferenciar: lo común y lo colectivo. Lo común se encuentra más bien ligado a un proceso de institucionalización de lo que debe ser mostrado, por lo que tiende a la homogeneidad y se constituye en memoria sesgada al instalar una memoria posible sobre lo que debe ser relevado. En tanto, lo colectivo refiere a una memoria que recoge la experiencia de lo microscópico, de la red cotidiana, de lo heterogéneo y plural de la ciudad vivida por generaciones; se trata de una forma de situarse, vivir y aprehender el espacio.
Por tanto, si hablamos de la ciudad que se abre a la patrimonialización es porque hay un interés y una gestión que pueden expresarse en esos términos. Así, la figura del patrimonio es coherente con el paso de ciudad a campamento, porque este último presupone la discontinuidad de la microhistoria que admite el cotidiano en su enlace pasado-presente-futuro; es decir, se enfrenta el fin de la ciudad viva para dar paso a la ciudad del recuerdo (o acabada), del documento, la ciudad museo, como estrategia política; quizá también del espectáculo como imagen de lo que algún día fue.

Esta operación simbólica fosiliza el cuerpo social y sustrae e invisibiliza a las otras memorias. Asimismo, se elude la relación crítica y analítica con el pasado que implica todo ejercicio de memoria. Entonces, por ejemplo, ¿cuál es el lugar de los viejos saberes y el valor del sindicato? Nada de esto puede ser registrado ni podrá sobrevivir a la amalgama funcional de ciudad-campamento-patrimonio; no se requiere ni del pasado ni de la historia. Sólo basta esta artificialización de la memoria y recordar en esa dirección para transformarla en un cuadro turístico.

\section{A MODO DE EPÍLOGO}

La vida durante décadas transcurre en esa placenta vital. Lejos queda el demiurgo que fundó la utopía. Se llega a un punto de no retorno, donde las claves son irreversibles conceptualmente. La figura de la Company Town desaparece no sólo del desierto de Atacama, sino que se transforma en una tendencia mundial, ya que ninguna empresa puede asumir los costes de la vida de personas no involucradas en las faenas; asimismo, las legislaciones ambientales que regulan las emisiones de procesos industriales y extractivos, y la valoración de indicadores de salud, comienzan a superar este modelo que hace un siglo era posible, eficiente y sustentable.

El cambio de concepto es lo que obliga a modificar las claves de vida. El desarrollo de este pequeño capullo en medio del desierto se transforma en la materia prima del recuerdo y del mito del paraíso en el que algún día se vivió. Sólo que hay conciencia de ello, pero no senti- 
miento de culpabilidad. Son la modernidad y la modernización de la industria minera las que fuerzan la salida de los hombres y mujeres de esta cultura del desierto. Éstos, en sus viviendas de las ciudades, más integrados a la vida nacional ya que podríamos decir que gozaron culturalmente durante décadas de cierto estatuto de extranjería, deben reconfigurar la propia identidad y las relaciones con la alteridad. Allí ya conocen de otras incertidumbres y riesgos, y su viejo saber podrá ser contado y recreado para dar paso a una nueva enunciación retórica y a otra mitografía.

\section{Bibliografía}

Anderson, Benedict, 2002, Las comunidades imaginadas, Fondo de Cultura Económica, México.

Augé, Marc, 2008, "Globalización, mediatización, urbanización. Travesías y ficciones de la antropología”, en Alejandro Bilbao y Patrice Vermeren (eds.), Política, ficción, subjetivación: figuras de lo humano, Ediciones Universitarias de Valparaíso, Valparaíso.

Bauman, Zigmunt, 2004, La globalización. Consecuencias humanas, Fondo de Cultura Económica, Buenos Aires.

Beck, Ulrich, 1998, La sociedad del riesgo. Hacia una nueva modernidad, Paidós, Buenos Aires.

Certeau, Michel de, 1999, La invención de lo cotidiano, 2 vols., Universidad Iberoamericana, Instituto Tecnológico y de Estudios Superiores de Occidente, México.

Chambers, Iain, 1994, Migración, cultura, identidad, Amorrortu, Buenos Aires.

Friedman, Jonathan, 1992, “The Past in the Future: History and the Politics of Identity", American Anthropologist, vol. 94, núm. 4, pp. 837-859.

Garcés, Eugenio, 1999, Las ciudades del salitre, Orígenes, Santiago.

Giddens, Anthony, 1994, Las consecuencias de la modernidad, Alianza, Madrid.

Hiernaux, Daniel, 2007, "Paisajes fugaces y geografías efímeras en la metrópolis contemporánea”, en Joan Nogué (ed.), La construcción social del paisaje, Biblioteca Nueva, Madrid, pp. 237-258.

Iranzo, Consuelo y Marcia de Paula Leite, 2006, "La subcontratación laboral en América Latina”, en Enrique de la Garza (coord.), Teorías sociales y estudios del trabajo: nuevos enfoques, Anthropos, Universidad Autónoma MetropolitanaIztapalapa, Barcelona, pp. 268-288.

Jameson, Fredric, 1991, El posmodernismo, la lógica cultural del capitalismo avanzado, Paidós, Barcelona.
Lindón, Alicia, 2007, "La construcción social de paisajes invisibles y del miedo", en Joan Nogué (ed.), La construcción social del paisaje, Biblioteca Nueva, Madrid, pp. 213-236.

Lynch, Kevin, 2008 [1998], La imagen de la ciudad, Gustavo Gili, Barcelona.

Maisonneuve, Jean, 2005, Las conductas rituales, Nueva Visión, Buenos Aires.

Martín Juez, Fernando, 2007, "El lugar de la bifurcación”, en Rafael Pérez-Taylor, Miguel Olmos y Hernán Salas (eds.), Antropología del desierto. Paisaje, naturaleza y sociedad, Instituto de Investigaciones Antropológicas, Universidad Nacional Autónoma de México, El Colegio de la Frontera Norte, México, pp. 15-33.

Rodríguez, Juan Carlos, Pablo Miranda y Pedro Mege, 2002, "Etnografía de la Siberia Caliente. Una nota metodológica sobre un estudio en María Elena, el último pueblo salitrero", Estudios Atacameños, núm. 22, Instituto de Investigaciones Arqueológicas, Museo R. P. Gustavo Le Paige, Universidad Católica del Norte, San Pedro de Atacama, pp. 105-126.

Rodríguez Torrent, Juan Carlos, 2004, "La reinvención del paraíso: sueño y olvido en los habitantes de los últimos pueblos salitreros del desierto de Atacama, Chile", en Desierto $y$ fronteras. El norte de México y otros contextos culturales, $\mathrm{V}$ Coloquio Paul Kirchoff, Universidad Nacional Autónoma de México, Instituto de Investigaciones Antropológicas, Plaza y Valdés, México, pp. 123-152.

_ 2007 , "Duelo y sentido de lo trágico en la tierra del nitrato. Los últimos trabajadores del salitre buscando un lugar", en Rafael Pérez-Taylor, Miguel Olmos y Hernán Salas (eds.), Antropología del desierto. Paisaje, naturaleza y sociedad, Instituto de Investigaciones Antropológicas, Universidad Nacional Autónoma de México, El Colegio de la Frontera Norte, México, pp. 247-280.

_ y Pablo Miranda, 2008, "Tiempo industrial y tiempos sociales en María Elena, la última ciudad del salitre", Chungará. Revista de Antropología Chilena, vol. 40, núm. 1, enero-junio, Universidad de Tarapacá, Arica, pp. 81-97.

Linhart, Danièle, 2007, "Ayer solidarios, ahora rivales", en El trabajo, Le Monde Diplomatique, Aún Creemos en los Sueños, Santiago, pp. 23-29.

Lucena, Héctor, 2006, “Las nuevas relaciones industriales”, en Enrique de la Garza (coord.), Teorías sociales y estudios del trabajo: nuevos enfoques, Editorial Anthropos y Universidad Autónoma Metropolitana-Iztapalapa, España, pp. 207221.

Sontag, Susan, 2006, Sobre la fotografía, Alfaguara, Buenos Aires.

Zapata, Francisco, 2002, "Los mineros como actores sociales y políticos en Bolivia, Chile y Perú durante el siglo Xx", Estudios Atacameños, núm. 22, Instituto de Investigaciones Arqueológicas, Museo R. P. Gustavo Le Paige, Universidad Católica del Norte, San Pedro de Atacama, pp. 91-103. 